\title{
Numerical analysis of compound heat transfer enhancement by single and two-phase models in parabolic through solar receiver
}

\author{
Amina Benabderrahmane*, Abdelylah Benazza**, Samir Laouedj***, J.P. Solano**** \\ *Faculty of Technology, Djillali Liabes University, Sidi Bel Abbes, Algeria, E-mail: amina.benabderrahmane@yahoo.fr \\ **Faculty of Technology, Djillali Liabes University, Sidi Bel Abbes, Algeria, E-mail: abdel_benazza@yahoo.fr \\ ***Faculty of Technology, Djillali Liabes University, Sidi Bel Abbes, Algeria, E-mail: samirladz@yahoo.fr \\ ****Ingeniería Térmica y de Fluidos, Universidad Politécnica de Cartagena, Spain, E-mail: juanp.solano@upct.es \\ cross $^{\text {ref }}$ http://dx.doi.org/10.5755/j01.mech.23.1.14053
}

\section{Introduction}

Recent advancement in nanotechnology have allowed development of a new class of fluids called nanofluid, which is considered of nanoparticles (oxide ceramics, metals, nonmetals, nitrides...) suspended in base fluid (water, oils, coolants, bio-fluids...). Nanofluids have interesting properties that make them potentially useful in many industrial applications as well enhancing heat transfer. Godson et al. [1], Weng et al. [2], Wang and Mujumdar [3], Duangthongsuk and Wongwises [4], Mohamed et al. [5], Kakaç et al. [6], Saidur et al. [7] presented reviews of nanofluids for heat transfer application; they concluded that nanofluids enhance greatly convective heat transfer.

The researches on the application of nanofluids have been popularized recently; various authors have investigated experimentally and numerically the effect of using nanofluid on heat transfer enhancement and flow characteristics. The numerical study has taken an important place in the field of fluid mechanics and heat transfer. Indeed it is an efficient and easy way to study the different physical phenomena and to prepare the sizing minimizing costs experimental tests. Furthermore numerical simulation also provides access to local quantities which is rarely possible in the case of an experimental study.

Generally there are two types of nanofluid convective heat transfer modeling, the single-phase simulation in which nanoparticles and base fluid are considered as homogenous with novel properties taking into consideration liquid and solid properties and two-phase modeling which the nanoparticles and base fluid are considered separately. Sokhansefat et al. [8] studied the effect of using $\mathrm{Al}_{2} \mathrm{O}_{3} /$ synthetic oil in a PTC tube, reporting that heat transfer augments for increasing nanoparticle volume fraction and operational temperature. Risi et al. [9] presented the heat transfer enhancement for $\mathrm{CuO}+\mathrm{Ni} /$ nitrogen gas in a PTC tube, demonstrating that above $0.3 \%$ vol the drawback effect of pressure drop overwhelm the beneficial effects of thermal properties, additionally the optimization procedure found a maximum solar to thermal efficiency equal to $62.5 \%$. Moghari et al. [10] studied on laminar mixed convection in horizontal annulus with constant heat flux at the inner and outer walls. Effects of nanoparticle concentration, Grashof number and heat flux ratio have been illustrating on hydrodynamic and thermal characteristics. Bianco et al. [11] focused the laminar flow of alumina/water nanofluid under constant wall heat flux by using the single phase and two-phase models; they declared that the two approaches give considerably the same results when the change on thermo-physical properties as function of temperature is taken into consideration. Madhesh et al. [12] experimentally proved that the convective heat transfer coefficient of nanofluids increased with increasing $\mathrm{Cu}$ $\mathrm{TiO}_{2}$ hybrid nanofluid concentration and the Reynolds number. They proposed a new Nusselt number correlation as a function of Reynolds number, Prandtl number and volume concentration of the hybrid nanofluid. Hussein et al. [13] studied numerically the laminar forced convection of $\mathrm{SiO}_{2}$ /water demonstrating that the increase of Nusselt number and friction factor depend on increasing volume fraction. Elias et al. [14] established the effect of different particle shapes in laminar flow; they predicted that cylindrical shape nanoparticle give best heat transfer performance. Duangthongsuk and Wongwises [4] investigated experimentally the forced convective heat transfer in a horizontal double-tube, their results shows that the heat transfer coefficient of nanofluid augments $26 \%$ and the pressure drop increases with increasing volume fraction. Akbari et al. [15] presented numerical modeling of laminar mixed convection of alumina/ water inside horizontal tube with uniform heat flux using single phase and two-phase approach; they concluded that two-phase model results are closer to the experimental data but very different than that obtained by homogenous phase. Lotfi et al. [16] compared the single phase with mixture and Eurelian two-phase models for forced convection flow of $\mathrm{Al}_{2} \mathrm{O}_{3}$ for $1 \%$ volume fraction; they found that mixture model is the most precise.

The present study was therefore undertaken to examine the turbulent forced convection of alumina/ dowtherm-A nanofluid inside a non-uniformly heated parabolic trough solar collector receiver equipped by two longitudinal fins, both the single phase and two-phase models are employed. The impact of particle diameter on heat transfer enhancement using two-phase mixture model has been studied.

\section{Physical model}

In this study, we considered a simple model of receiver of the parabolic trough solar collector which is shown in Fig. 1.

To improve the heat transfer inside PTC receiver, two longitudinal rectangular fins are inserted where the heat flux is higher in the absorber tube which is illustrated in Fig. 2. The materials used for the glass cover and the absorber are borosilicate glass and steel respectively, the 
annular space between the both is considered as vacuum at lower pressure and ambient temperature. The physical parameters used in this paper are given in Table 1.

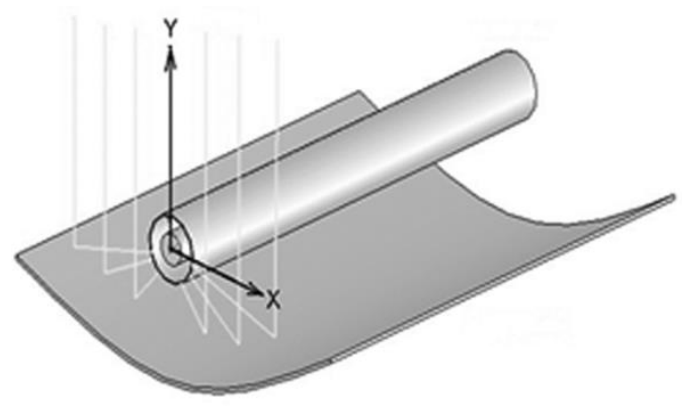

Fig. 1 PTC receiver

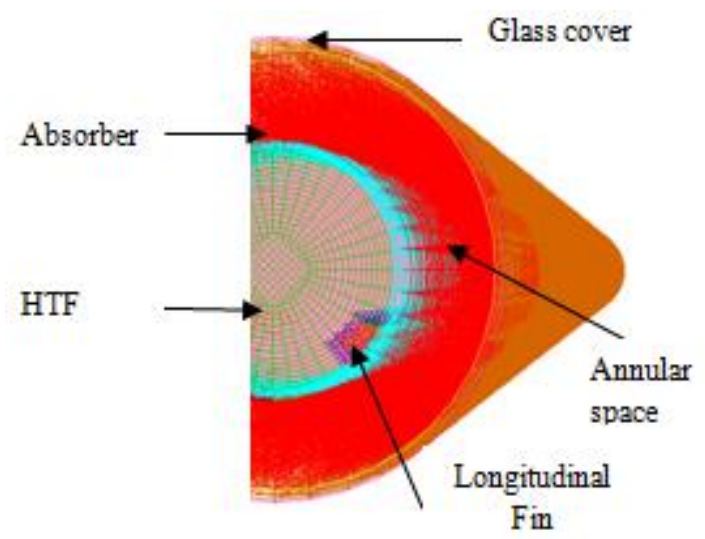

Fig. 2 Schematic of PTC receiver with longitudinal fins inserts

Table 1

Receiver dimensions

\begin{tabular}{|l|r|}
\hline Focal length & $1710 \mathrm{~mm}$ \\
\hline Aperture width & $5770 \mathrm{~mm}$ \\
\hline Absorber inner radius & $32 \mathrm{~mm}$ \\
\hline Absorber outer radius & $35 \mathrm{~mm}$ \\
\hline Glass cover inner radius & $59.6 \mathrm{~mm}$ \\
\hline Glass cover outer radius & $62.5 \mathrm{~mm}$ \\
\hline Material of the absorber & Steel \\
\hline Material of the glass envelope & Borosilicate \\
\hline Transmittance of glass cover & $>96 \%$ \\
\hline Coating absorbance & $95 \%$ \\
\hline Glass cover emissivity & 0.837 \\
\hline
\end{tabular}

\section{Numerical model}

The numerical simulation is performed using the finite volume method using ANSYS. [17] The K- $\mathcal{E}$ turbulent model was used. Pressure based solver is used to solve the pressure based equation, PRESTO and QUICK scheme are used for pressure and volume fraction respectively; for other equations, first order upwind is adopted. Simple algorithm is used for pressure-velocity coupling.

\subsection{Heat transfer fluid properties}

The HTF used in this study is nanofluid coxnsist- ing of Alumina nanoparticles suspended in synthetic oil Dowtherm-A.

\subsubsection{Single phase model}

According to the data in literature, there are different types of models for nanofluid thermo-physical characteristics. In our study we used the following formulas to calculate nanofluid's thermo-physical properties.

a) density[18]:

$$
\rho_{n f}=(1-\phi) \rho_{p}+\phi \rho_{f}
$$

b) heat capacity [19]:

$$
C_{p_{n f}}=(1-\phi) C_{p_{p}}+\phi C_{p_{f}}
$$

c) thermal conductivity [20]:

$$
\lambda_{n f}=\lambda_{f}\left[1+4.4 \operatorname{Re}_{p}^{0.4} \operatorname{Pr}_{f}^{0.66}\left(\frac{T}{T_{f r}}\right)^{10}\left(\frac{\lambda_{p}}{\lambda_{f}}\right)^{0.03} \phi^{0.66}\right]
$$

where $R e_{p}$ is nanoparticle Reynolds number defined as:

$$
R e_{p}=\frac{2 \rho_{f} k T}{\pi \mu_{f}^{2} d_{p}}
$$

$T_{f r}$ is freezing point of base fluid $(285.15 \mathrm{~K}) ; k$ is Boltzmann constant;

d) dynamic viscosity [21]:

$$
\mu_{n f}=\frac{\mu_{f}}{(1-\phi)^{5 / 2}} .
$$

\subsubsection{Two-phase approach}

In the present paper, numerical simulation of nanofluid flow is performed comparing the single phase homogenous nanofluid with two-phase mixture and twophase VOF. Two-phase numerical method assumes local equilibrium over short spatial length scales. The nanoparticle phase is considered to be interpenetrating continua its viscosity was obtained from the experimental data of Miller and Gidaspow [22] defined as follow:

$$
\mu_{p}=-0.188+537.42 \phi
$$

\subsubsection{Volume of fluid model}

The VOF model is designed to track the location and motion of a free surface between two or more immiscible fluids. In this model all properties are calculated by taking a weighted average of multiple phases based on their volume fraction. Continuity, momentum and energy equations are defined as:

$$
\nabla\left(\phi_{k} \rho_{k} \vec{V}_{k}\right)=0,
$$

where $\sum_{k=1}^{n} \phi_{k}=1$ 


$$
\begin{aligned}
& \rho \vec{V} \nabla \vec{V}=-\nabla P+\nabla(\mu \nabla \vec{V})+\rho g ; \\
& \nabla(\vec{V}(\rho E+P))=\nabla(K \nabla T) .
\end{aligned}
$$

\subsubsection{Mixture model}

The mixture model is a simplified Eulerian approach, based on the assumption of small Stokes number. It solves the mixture momentum equation as well volume fraction transport equation for each secondary phase. The equations are defined as:

- conservation of mass:

$$
\nabla\left(\rho_{m} \overrightarrow{V_{m}}\right)=0
$$

- conservation of energy:

$$
\nabla \sum_{k=1}^{n}\left(\rho_{k} C_{p k} \phi_{k} V_{k} T\right)=\nabla\left(K_{m} \nabla T\right)
$$

- conservation of momentum:

$$
\begin{aligned}
& \rho_{m} \overrightarrow{V_{m}} \nabla \overrightarrow{V_{m}}=-\nabla P_{m}+\left(\mu_{m} \nabla \overrightarrow{V_{m}}\right)+\rho_{m} g+ \\
& +\nabla\left(\sum_{k=1}^{n} \phi_{k} \rho_{k} \vec{V}_{d r, k} \vec{V}_{d r, k}\right),
\end{aligned}
$$

where drift velocity of $k$-th phases is calculated as:

$$
\vec{V}_{d r, k}=\vec{V}_{k}-\vec{V}_{m}
$$

Mixture properties are defined as:

velocity: $\overrightarrow{V_{m}}=\frac{\sum_{k=1}^{n} \phi_{k} \rho_{k} V_{k}}{\rho_{m}}$;

density: $\rho_{m}=\sum_{k=1}^{n} \phi_{k} \rho_{k}$

viscosity: $\mu_{m}=\sum_{k=1}^{n} \phi_{k} \mu_{k}$;

- volume fraction:

$$
\nabla\left(\rho_{p} \phi_{p} \vec{V}_{m}\right)=-\nabla\left(\rho_{p} \phi_{p} \vec{V}_{d r, p}\right)
$$

The relative velocity is defined by Mannien et al. [23] correlation as follow:

$$
\vec{V}_{p f}=\frac{\tau_{p} d_{p}^{2}}{18 \mu_{f} f_{\text {drag }}} \frac{\left(\rho_{p}-\rho_{m}\right)}{\rho_{p}} \vec{a},
$$

where $\mathrm{a}$ is the acceleration defined as:

$$
\vec{a}=\vec{g}-\left(\overrightarrow{V_{m}} \cdot \nabla\right) \vec{V}_{m}
$$

$f_{\text {drag }}$ is drag function calculated by Shiller and Nauman [24] correlation in the form of:

$$
\left\{\begin{array}{l}
f_{\text {drag }}=1+0.15 \operatorname{Re}_{p}^{0.687} \text { when } R e_{p} \leq 1000 \\
f_{\text {drag }}=0.0183 \operatorname{Re}_{p} \text { when } R e_{p}>1000
\end{array}\right.
$$

where $R e_{p}$ is nanoparticle Reynolds number given by:

$$
R e_{p}=\frac{\rho_{m} V_{m} d_{p}}{\mu_{m}} .
$$

\subsection{Numerical modeling}

For the present numerical investigation, the outer absorber's wall receives a non-uniform heat flux which is obtained by using Monte-Carlo ray tracing [25] where the DNI of $1000 \mathrm{~W} / \mathrm{m}^{2}$ was used. The simulation results of the local concentration ratio distribution on a cross section of the absorber outer surface are shown in Fig. 3; symmetry boundary condition is used for the inlet and outlet annular space. For the outer glass envelope, a thermal boundary condition that includes the convection and radiation heat transfer is used.

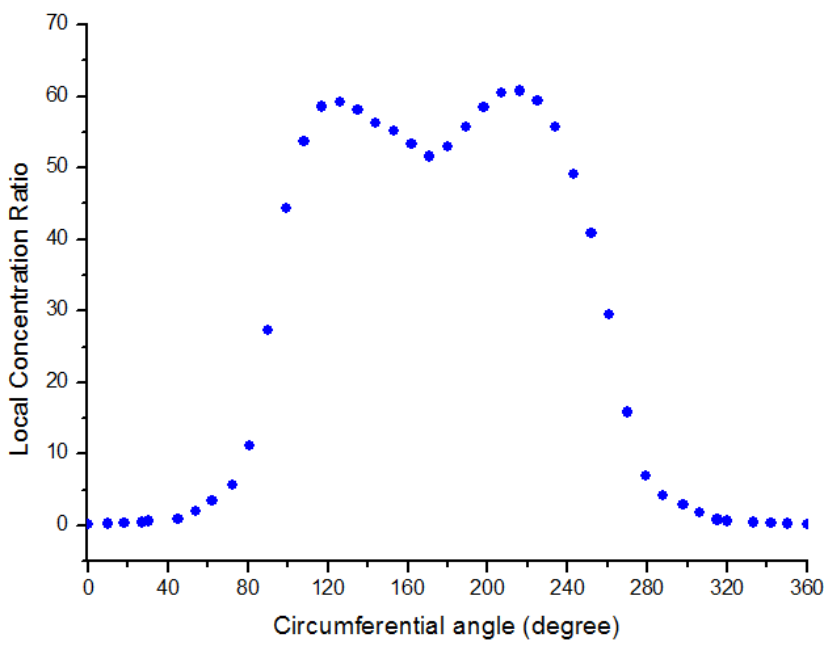

Fig. 3 The local concentration ratio on a cross-section of the absorber outer surface

Sky temperature can be calculated using the following correlation [26]:

$$
T_{s k y}=0.0552 T_{a m b}^{1.5},
$$

where the ambient temperature used in this simulation is $300 \mathrm{~K}$ and $T_{d p}$ is dew point temperature $(\mathrm{K})$.

Additionally, the convection heat transfer coefficient used for the boundary condition is defined by the experimental correlation [27]:

$$
h_{w}=4 v_{w}^{0.58} d_{g o}^{-0.42},
$$

where $v_{w}$ is the wind speed ( $2 \mathrm{~m} / \mathrm{s}$ in this study) and $d_{g o}$ is the glass cover outer diameter.

\section{Results and discussion}

\subsection{Validation of numerical results}

To attain the confidence about the numerical re- 
sults, we compared the simulation data for a smooth absorber with the correlations existing in literature. We chose mixture two-phase model, in which the primary phase is Dowtherm-A and the second phase is Alumina nanoparticle with $1 \%$.vol and $13 \mathrm{~nm}$ diameter at operational temperature of $573 \mathrm{~K}$, the results are shown in Fig. 4.

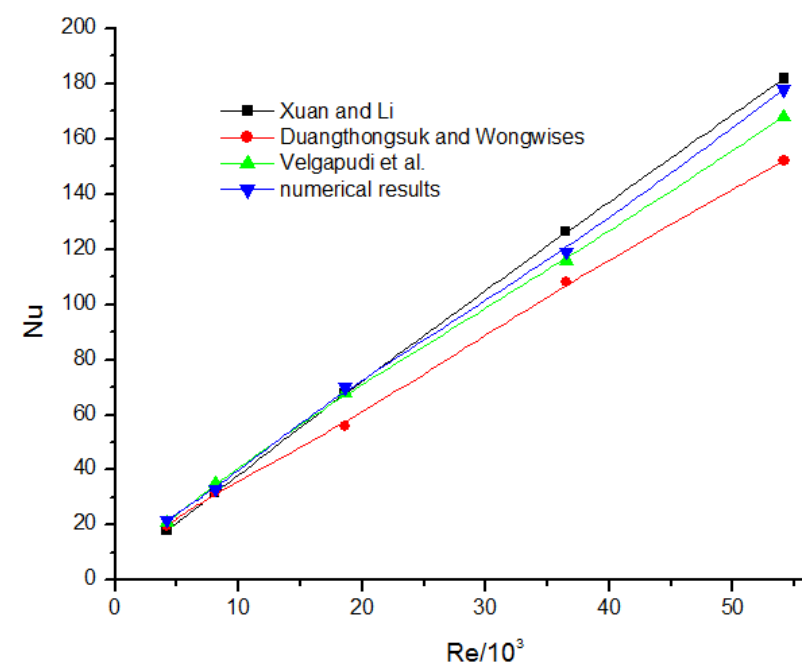

Fig. 4 Validation of numerical results for a smooth absorber

Xuan and Li (2003) [28] studied flow and convective heat transfer of the nanofluid in a tube; they introduced the following correlation for the calculation of average Nusselt number as function of Reynolds number, Prandtl number, Peclet number and nanoparticle volume fraction.

$$
N u=0.0059\left(1+7.628 \phi^{0.6886} P e_{P}^{0.001}\right) R e^{0.9238} \operatorname{Pr}^{0.4},
$$

where $P e_{p}=\frac{v d}{\alpha_{n f}}=\frac{v d \rho C_{p}}{\lambda} ; \alpha_{n f}$ is thermal diffusivity.

Velgapudi et al. (2008) [29] recommended a new correlation for turbulent flow only depending on Reynolds and Prandtl numbers as follow:

$$
N u=0.0256 \operatorname{Re}^{0.8} \operatorname{Pr}^{0.4}
$$

Duangthongsuk and Wongwises (2010) [4] experimentally investigated the heat transfer coefficient and friction factor of nanofluids in horizontal tube; they established the following correlation for predicting Nusselt number depending on Reynolds number, Prandtl number and nanoparticles concentration:

$$
N u=0.074 \operatorname{Re}^{0.707} \operatorname{Pr}^{0.385} \phi^{0.074} .
$$

Fig. 4 shows compatible results of average Nusselt number between the present numerical simulation results and the empirical correlations, especially Xuan and $\mathrm{Li}$ correlation when the maximum deviation is $5.3 \%$ for $R e=3.6 \times 10^{4}$, and the minimum error is $2.2 \%$ for $R e=1.8 \times 10^{4}$, so this results demonstrate a good agreement between our numerical results and those obtained by the correlations.

\subsection{Thermal performance analysis}

4.2.1. Effect of using longitudinal fins and nanofluid inside the absorber

Fig. 5 shows that absorber equipped with fins retrieves higher convective heat transfer coefficient than smooth tube especially where the fins are inserted; the Nusselt number augments between 1.3 to 1.8 times compared to the plain tube which means that the presence of the longitudinal fins improves heat exchange by increasing the surface of contact. Additionally, the use of compound enhancement technique based on using nanofluid and the two longitudinal fins in tube side of PTC offers better heat transfer which dues to the beneficial effect of fins and the higher thermal conductivity of nanoparticles.

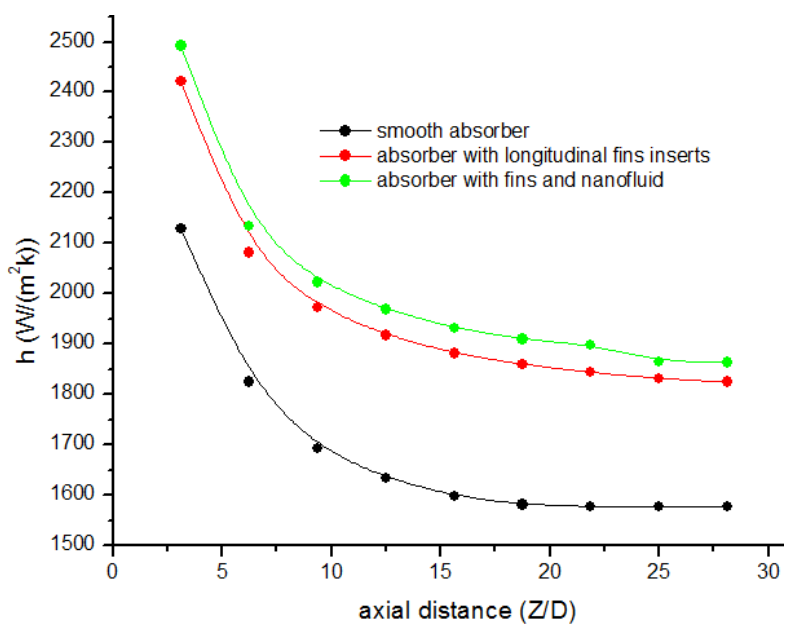

Fig. 5 Comparison of calculated local convective heat transfer coefficient for $R e=36338 ; \phi=0.01$

Fig. 6 presents the comparison of calculated local convective heat transfer coefficient between the single and two-phase models for, $\phi=1 \%$.vol and $d_{p}=13 \mathrm{~nm}$. Comparing this numerical results predicted by the homogenous and the two-phase models demonstrates that the single phase gives lower values than two-phase models however both two-phase models give almost the same results. The disagreement between the corresponding numerical data results obtained by the three models under consideration is probably due the accuracy of the effective thermo-physical properties used for the nanofluid homogenous phase.

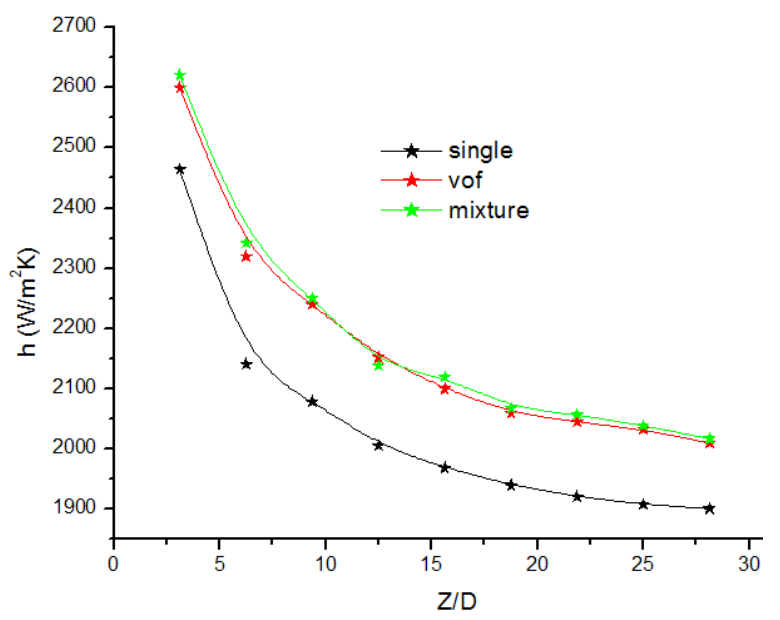

Fig. 6 Numerical results of Local convective heat transfer coefficient of single and two-phase models 
Fig. 7 illustrates the contours of temperature on the middle cross-section of the absorber when the DNI of $1000 \mathrm{~W} / \mathrm{m}^{2}$ was used at HTF inlet temperature of $573 \mathrm{~K}$. The higher fluid's temperature on the bottom is due to the non-uniform heat flux distribution.

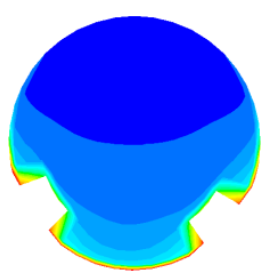

Single phase

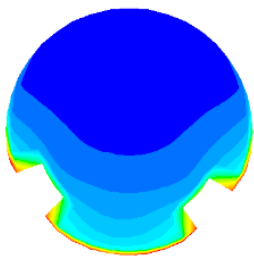

VOF model

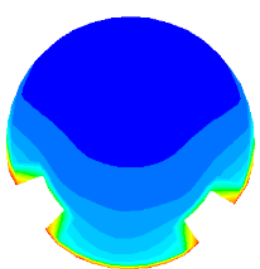

Mixture model

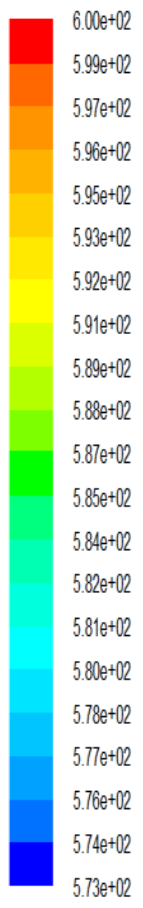

$5.73 e+02$
Fig. 7 Temperature distribution on the middle of the absorber

It can be obviously seen that the temperature contours predicted by the three models are qualitatively similar, demonstrating that the difference between Nusselt number results isn't due to the fluid temperature.

On the other hand, the temperature distributions along the radial direction on the middle cross-section of the absorber for the three models at the same conditions are presented. It can be found from Fig. 8 that the two-phase models give considerably similar values lower than that obtained in the case of single phase which decreases the temperature gradient which induces an improvement in the heat transfer coefficient.

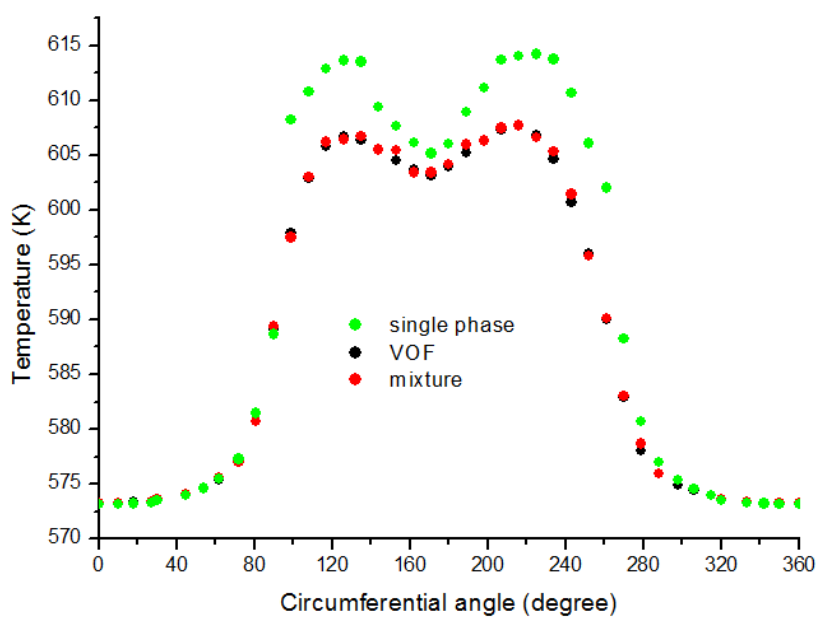

Fig. 8 Temperature distribution on the middle cross-section of the absorber wall
Fig. 9 depicts the progression of local Darcy friction factor along the tube length, which is defined as:

$$
f_{x}=\frac{8 \tau_{w(x)}}{\rho u^{2}},
$$

where $\tau_{w(x)}$ is local wall shear stress and $\mathrm{u}$ is axial velocity.

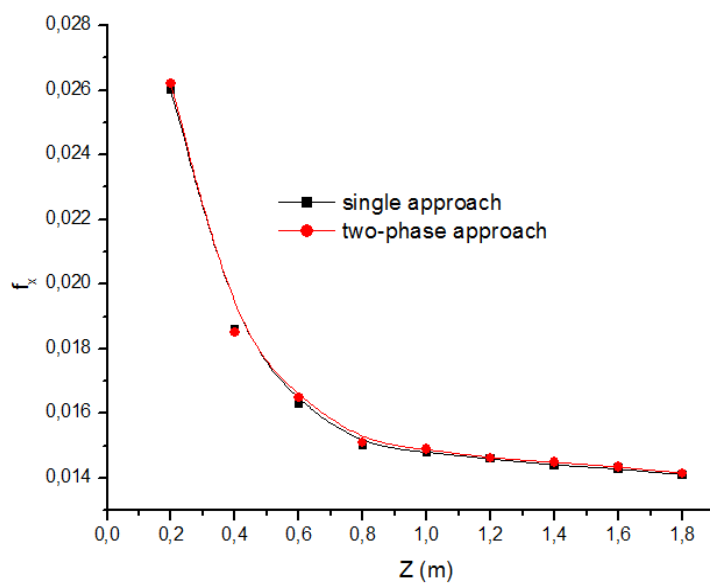

Fig. 9 Local Darcy friction factor of single and two-phase model for $R e=36340$ and $\phi=0.01$

According to Fig. 9, the single phase and twophase models give almost quite close results of local Darcy friction factor when the maximum change is around $2.7 \%$. From these results, it can be concluding that two-phase and single phase models predict almost identical hydrodynamic results but dissimilar thermal ones.

\subsubsection{Impact of nanoparticles mean diameter on heat transfer}

In this part, two-phase mixture model was employed to investigate the effect of nanoparticle's size on the flow characteristics. For a given Reynolds number, nanoparticle's volume fraction $(\phi=0.01)$ and four values of $\mathrm{Al}_{2} \mathrm{O}_{3}$ particle diameter $(13,30,70$ and $100 \mathrm{~nm})$, the evolution of the local Nusselt number along the tube length is shown in Fig. 10. It can be seen that decreasing the particles diameter causes to increase the Nusselt number this is due to the aggregation of nanoparticles and stronger Brownian motion at smaller nanoparticles diameters, which leads to higher thermal conductivity of nanofluids so obviously a better heat transfer.

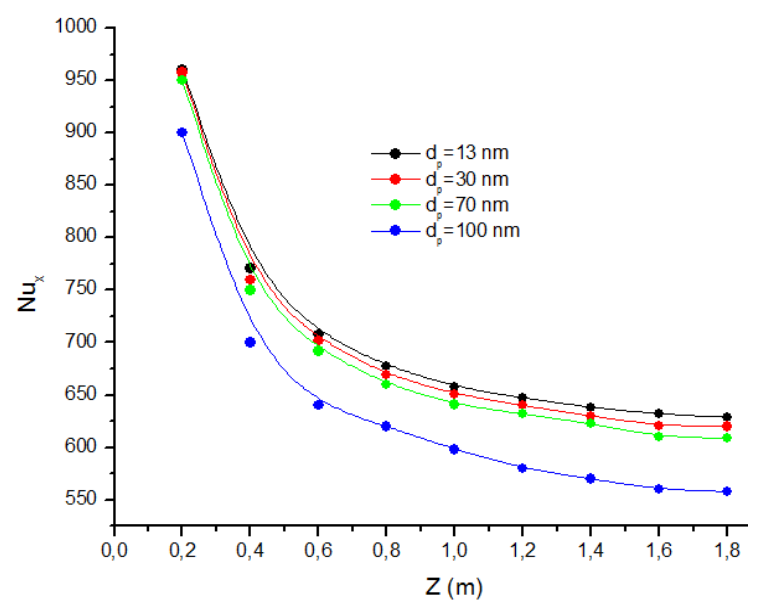

Fig. 10 Local Nusselt number for various particle diameters 


\section{Conclusion}

Turbulent forced convection of alumina/ dowtherm-A inside a PTC receiver with the presence of two longitudinal fins in the absorber was studied. The flow field was predicted numerically using the single phase and two-phase mixture and VOF models. For validate purposes the numerical results was compared with those obtained by the correlations existing in literatures for different Reynolds number and good agreement is observed between them. The effect of nanoparticle size on thermal performance was focused; ultimately the following results were obtained:

1. The use of compound enhancement technique based on using of nanofluid and the two longitudinal fins in tube side of PTC offer better heat transfer. are closer.

2. The predictions by the two two-phase models

3. The evolution of local convective heat transfer coefficient gives very different results for the single and two-phase modeling however the results of Darcy friction factor are considerably similar which mean that the singlephase model still needs to be modified.

4. The heat transfer fluid temperature is qualitatively the same for the homogenous and two-phase models though the absorber temperature is higher in the case of homogenous phase.

5. The most important benefit two-phase method in comparison to homogenous modeling is that there is no need for effective thermo-physical properties for the nanofluid.

6. The enhancement of convective heat transfer resulting from small nanoparticle diameter.

\section{References}

1. Godson Raja, L.; Mohan Lal, B.; Wongwises, D.S. 2010. Enhancement of heat transfer using nanofluidsAn overview, Renewable and Sustainable Energy Reviews 14: 629-41. http://dx.doi.org/10.1016/j.rser.2009.10.004.

2. Wen, D.; Lin, G.;Vafaei, S.; Zhang, K. 2009 Review of nanofluids for heat transfer applications, Particuology 7: 141-150. http://dx.doi.org/10.1016/j.partic.2009.01.007.

3. Wang, X.Q.; Mujumdar, A.S. 2006 Heat transfer characteristics of nanofluids: a review, Journal of Thermal Science 46: 1-19. http://dx.doi.org/10.1016/j.ijthermalsci.2006.06.010.

4. Duangthongsuk, W.; Wongwises, S. 2010 An experimental study on the heat transfer performance and pressure drop of $\mathrm{TiO}_{2}$-water nanofluids flowing under a turbulent flow regime, International Journal of Heat and Mass Transfer 53: 334-344.

http://dx.doi.org/10.1016/j.ijheatmasstransfer.2009.09.0 24.

5. Mohammed, H.A.; Bhaskaran, G.; Shuaib, N.H.; Saidur, R. 2011 Heat transfer and fluid flow characteristics in microchannels heat exchanger using nanofluids: a review, Renewable and Sustainable Energy Reviews 15: 1502-1512. http://dx.doi.org/10.1016/j.rser.2010.11.031.

6. Kakac- S.; Pramuanjaroenkij, A. 2009 Review of convective heat transfer enhancement with nanofluids,
International Journal of Heat and Mass Transfer 52: 3187-3196.

http://dx.doi.org/10.1016/j.ijheatmasstransfer.2009.02.0 06.

7. Saidur, R.; Leong, K.Y.; Mohammad, H.A. 2011. A review on applications and challenges of nanofluids, Renewable and Sustainable Energy Reviews 15: 16461668. http://dx.doi.org/10.1016/j.rser.2010.11.035.

8. Sokhansefat, T.; Kasaeian, A.B.; Kowsary, F. 2014. Heat transfer enhancement in parabolic trough collector tube using $\mathrm{Al}_{2} \mathrm{O}_{3}$ /synthetic oil nanofluid, Renewable and Sustainable Energy Reviews 33: 636-644. http://dx.doi.org/10.1016/j.rser.2014.02.028.

9. De Risi, A.; Milanese, M.; Laforgia, D. 2013. Modelling and optimization of transparent parabolic trough collector based on gas-phase nanofluids, Renewable Energy 58: 134-139. http://dx.doi.org/10.1016/j.renene.2013.03.014.

10. Mokhtari Moghari, R.; Akbarinia, A.; Shariat, M.; Talebi, F.; Laur, R. 2011Two phase mixed convection $\mathrm{Al}_{2} \mathrm{O}_{3}$ /water nanofluid flow in an annulus, Int. J. Multiph. Flow 37: 585-595.

http://dx.doi.org/10.1016/j.ijmultiphaseflow.2011.03.00 8.

11. Bianco, V.; Chiacchio, F.; Manca, O., Nardini, S. 2009. Numerical investigation of nanofluids forced convection in circular tubes, Appl. Therm. Eng. 29: 3632-3642.

http://dx.doi.org/10.1016/j.applthermaleng.2009.06.019

12. Madhesh, D.; Parameshwaran, R.; Kalaiselvam, S. 2014. Experimental investigation on convective heat transfer and rheological characteristics of CueTiO2 hybrid nanofluids, Exp. Therm. Fluid Sci. 52: 104-115. http://dx.doi.org/10.1016/j.expthermflusci.2013.08.026

13. Hussein, A.M.; Bakar, R.A.; Kadirgama, K.; Sharma, K.V. 2014. Heat transfer enhancement using nanofluids in an automotive cooling system, Int. Commun. Heat Mass Transfer 53: 195-202.

http://dx.doi.org/10.1016/j.icheatmasstransfer.2014.01. 003 .

14. Elias, M.M.; Shahrul, I.M.; Mahbubul, I.M.; Saidur, R.; Rahim, N.A. 2014. Effect of different nanoparticle shapes on shell and tube heat exchanger using different baffle angles and operated with nanofluid, Int. J. Heat Mass Transfer 70: 289-297.

http://dx.doi.org/10.1016/j.ijheatmasstransfer.2013.11.0 18.

15. Akbari, M.; Galanis, N.; Behzamehr, A. 2014. Comparative analysis of single and two-phase models for CFD studies of nanofluid heat transfer, Int. J. Therm. Sci. 50: 1343-1354.

http://dx.doi.org/10.1016/j.ijthermalsci.2011.03.008.

16. Lotfi, R.; Saboohi, Y.; Rashidi, A.M. 2010. Numerical study of forced convective heat transfer of nanofluids: comparison of different approaches, Int. Commun. Heat Mass Transfer 37: 74-78. http://dx.doi.org/10.1016/j.icheatmasstransfer.2009.07. 013.

17. ANSYS Academic research, release 14.5, ANSYS FLUENT user's guide, ANSYS Inc.

18. Pak, B.C.; Cho, Y.I. 1998. Hydrodynamic and heat transfer study of dispersed fluids with submicron metallic oxide particles, Experimental Heat Transfer 
11: 151-170. http://dx.doi.org/10.1080/08916159808946559.

19. Wen, D.; Ding, Y. 2004. Experimental investigation into convective heat transfer of nanofluid at the entrance region under laminar flow conditions, International Journal of Heat and Mass Transfer 47: 51815188.

http://dx.doi.org/10.1016/j.ijheatmasstransfer.2004.07.0 12.

20. Corcione, M. 2011. Empirical correlating equations for predicting the effective thermal conductivity and dynamic viscosity of nanofluids, Energy Conversion and Management 52: 789-793. http://dx.doi.org/10.1016/j.enconman.2010.06.072.

21. Brinkman, H. 1952. The viscosity of concentrated suspensions and solutions, J. Chem. Phys. 20: 571-581. http://dx.doi.org/10.1063/1.1700493.

22. Miller, A.; Gidaspow, D. 1992. Dense, vertical gassolid flow in a pipe, AIChE J. 38(11): 1801-1815. http://dx.doi.org/10.1002/aic.690381111.

23. Manninen, M.; Taivassalo, V.; Kallio, S. 1996. On the mixture model for multiphase flow, VTT Publications 288, Technical Research Center of Finland.

24.Schiller, L.; Naumann, A. 1935. A drag coefficient correlation, Z. Ver. Deutsch. Ing. 77: 318-320.

25. NREL. SolTrace optical modeling software. SolTrace 2012; 2012.7.9; 2012.

26. García-Valladares, O.; Velázquez, N. 2009. Numerical simulation of parabolic trough solar collector: improvement using counter flow concentric circular heat exchangers, Int J Heat Mass Transfer 52: 597-609.

http://dx.doi.org/10.1016/j.ijheatmasstransfer.2008.08.0 04.

27. Mullick, S.C.; Nanda, S.K. 1989. An improved technique for computing the heat loss factor of a tubular absorber, Sol Energy 42: 1-7. http://dx.doi.org/10.1016/0038-092X(89)90124-2.

28. Xuan, Y.M.; Li, Q. 2003. Investigation on convective heat transfer and flow features of nanofluids, J. Heat Transfer 125: 151-155.

http://dx.doi.org/10.1115/1.1532008.
29. Velagapudi, V.; Konijeti, R.K.; Aduru, C.S.K. 2008. Empirical Correlations to Predict Thermo physical And Heat Transfer Characteristics of Nanofluids, Thermal Science 12(2): 27-37. http://dx.doi.org/10.2298/TSCI0802027V.

Amina Benabderrahmane, Abdelylah Benazza, Samir Laouedj, J.P. Solano

\section{NUMERICAL ANALYSIS OF COMPOUND HEAT TRANSFER ENHANCEMENT BY SINGLE AND TWO- PHASE MODELS IN PARABOLIC THROUGH SOLAR RECEIVER}

S u m m a r y

A three dimensional numerical investigation of turbulent forced convection of Alumina/dowtherm-A nanofluid inside a non-uniformly heated parabolic trough solar collector receiver equipped by two longitudinal fins for improving heat transfer by single and two-phase modeling has been carried out. The heat flux around the absorber tube was obtained applying Monte Carlo ray trace technique. The numerical results were validating with the empirical correlations existing in literatures and good agreement was obtained. The calculated results demonstrate that two-phase models predict a higher convective heat transfer coefficient however the predictions of Darcy friction factor by single and two-phase approaches are essentially the same. Two-phase mixture model has been used to investigate the influence of nanoparticles mean diameter on heat transfer phenomena; it found that a smaller nanoparticles increase better convective heat transfer.

Keywords: Numerical study; non-uniform heat flux; longitudinal fins; nanofluid; two-phase model.

Received January 28, 2016

Accepted February 06, 2017 